\title{
Changes in caffeine of fermented Liberica coffee beans cv. Liberoid Meranti on roasting levels
}

\author{
Nendyo Adhi Wibowo ${ }^{1,2 *}$, Wibowo Mangunwardoyo ${ }^{1}$, Tri Joko Santoso ${ }^{2}$, and Yasman ${ }^{1}$ \\ ${ }^{1}$ Department of Biology, Faculty of Mathematics and Science, Universitas Indonesia, Depok, West \\ Java, Indonesia 16424 \\ ${ }^{2}$ Indonesian Industrial and Beverages Crops Research Institute (IIBCRI), Jl. Raya Pakuwon Km 2 \\ Parungkuda, Sukabumi, Indonesia 43357
}

\begin{abstract}
One of the varieties of Liberica coffee in Indonesia is the Liberoid Meranti coffee. Fermentation technology and the roasting temperature of Liberica coffee are needed in changing the composition of caffeine in coffee beans. The aim of this research was to see the caffeine content of the Liberica coffee beans cv. Liberoid Meranti fermented by hydrolytic bacteria on levels at a light, medium, and dark roasting temperatures. Coffee fermentation was carried out using the wet processing method and a roasting temperature of $150^{\circ} \mathrm{C}, 175^{\circ} \mathrm{C}, 200^{\circ} \mathrm{C}$, and caffeine analysis was carried out by UV-Visible spectrophotometry. The data obtained from each parameter based on roasting levels were processed using the statistical application of Minitab version 16 for Windows and analyzed using ANOVA with a level of 5\%. If there is a significant difference from the F-test result $(\mathrm{p}<0.05)$, then proceed with the post hoc test. The results showed that all samples contain large amounts of caffeine with various concentrations. The level concentration of caffeine in light roast samples in the range of $10,80 \mathrm{ppm}-12,52 \mathrm{ppm}$, medium roast samples in the range of $11,46 \mathrm{ppm}-14,08 \mathrm{ppm}$, and dark roast samples in the range of $14,49 \mathrm{ppm}-$ $16,94 \mathrm{ppm}$. The caffeine content in fermented Liberica coffee bean experienced a significant difference. The fermentation and roasting process of coffee beans is a complex compound process that can cause changes in caffeine levels.
\end{abstract}

\section{Introduction}

Coffee is a beverage from processing in the form of coffee bean extraction. The coffee cherries are de-fleshed and the seeds inside the coffee are dried and roasted to develop the color, aroma and taste of the coffee [1]. The production of Indonesian coffee commodities is dominated by robusta coffee which reaches $90 \%$ and arabica coffee by $10 \%$. Meanwhile, for the world market, it is $85 \%$ arabica coffee, $10 \%$ robusta coffee, and $5 \%$ for liberica and excelsa coffee [2]. Indonesia produced coffee exports with a volume of 467800 tons in 2017

* Corresponding author: nendyo.adhi@gmail.com 
[3]. The name coffee comes from the word Keffa which comes from the name of the early province of coffee discovered by a shepherd from Ethiopia in the 6th century [4].

Caffeine $(1,3,7$-trimethylxanthine; $\mathrm{Mr}=194)$ is a secondary metabolite compound that has stimulant properties for the central nervous system, muscles and kidneys. Caffeine with the chemical formula $\mathrm{C}_{8} \mathrm{H}_{10} \mathrm{~N}_{4} \mathrm{O}_{2}$ is slightly soluble in water, with acids it can react to form unstable salts, and in bases it will form stable salts. Caffeine is produced naturally by at least 80 plant species, although usually only in small amounts [5]. Caffeine in coffee plants is distributed in coffee beans, leaves and not in roots [6]. Caffeine acts as a central nervous system stimulant that increases alertness, reduces the need for sleep, and increases the effectiveness of some medications, so it is used with some over-the-counter medications to treat migraines [7]. Caffeine also has a deficiency, caffeine can increase blood pressure, diuresis, increased blood sugar, increased gastric acid and pepsin secretion, calcium loss which causes bone loss, and can cause death if consumed more than $1 \mathrm{~g} /$ day [7]. Caffeine is a good stimulant and can activate circulation and respiration; it also has a weak diuretic effect. Including its use with aspirin to treat headaches [1].

Caffeine content in coffee varies based on geographic location which determines soil type, rainfall, and other environmental conditions [1]. In addition to Arabica and Robusta coffee, the new type of Liberica coffee found in Indonesia is Liberoid Meranti [8]. Coffee does not always contain caffeine, there are also types of wild coffee that contain little or no caffeine such as Mascarocoffea sp. and Coffea eugenioides [6]. There are 3 levels of coffee roasting, namely light roasting with a temperature range of $193-199^{\circ} \mathrm{C}$, medium roasting (medium roasting) with a temperature range of $204^{\circ} \mathrm{C}$, and heavy roasting (dark roast) with a temperature range of $213-221^{\circ} \mathrm{C}$. The roasting temperature used will affect the water content, acidity, taste, aroma, and color. Roasting aims to reduce the water content, cause color changes, and form a specific aroma [9].

The Liberica coffee fermentation on roasting levels was chosen due to the caffeine role in sensory quality. It is expected to lead to a new perspective on coffee quality other than traditional coffee and general roasting, greater diversification of flavors. This study aims to determine the content of caffeine changes to get the sensory quality of fermented Liberica coffee beans cv. Liberoid Meranti (LiM) on levels at light, medium, and dark roasting temperatures.

\section{Materials and methods}

\subsection{Materials}

Raw materials in the form of coffee fruit Liberica cv. Liberoid Meranti 1 (LiM 1) harvested red picking and selected from the fruit defects, then peeled the skin of the fruit with a pulper machine. A sampling of Liberica cv. LiM 1 coffee fruit was conducted at Pakuwon experimental garden owned by the Indonesian Industrial and Beverages Crops Research Institute (IIBCRI). The bacterial consortium consists of Lysinibacillus fusiformis strain MaSu CECRI 2, Bacillus cereus strain L77, Bacillus subtilis strain GL2 and Bacillus cereus strain F4a. The research was conducted in Integrated Laboratory IIBCRI, Indonesian Agency for Agricultural Research and Development, Ministry of Agriculture Republic Indonesia, on Jalan Raya Pakuwon KM 2 Parungkuda, Sukabumi, West Java, Indonesia.

\subsection{Preparation of fermentation}

Coffee fruit Liberica cv. Liberoid Meranti (LiM) prepared as much as $10 \mathrm{~kg}$ of each peeled fruit LiM 1 for each fermentation treatment with the addition of $10 \%$ consortium of bacteria. 
The samples were collected at intervals $0,4,8$, and $12 \mathrm{~h}$ of fermentation. Fermentation was performed in a wet process and carried out in triplicate. Each fermentation at the following time treatment :

$\mathrm{F} 0=$ Non fermented for 0 hours (without fermentation)

$\mathrm{F} 1=$ Fermented for 4 hours.

$\mathrm{F} 2=$ Fermented for 8 hours

$\mathrm{F} 3=$ Fermented for 12 hours

\subsection{Moisture content thermogravimetric}

Coffee beans were dried until the water content reaches $\leq 12 \%$ and it is carried outstripping the skin of coffee horns with a peeling machine. The moisture of water content of fermented coffee analysis samples by drying an empty weight bottle (wb) in an oven temperature of $100 \pm 5^{\circ} \mathrm{C}$ for 30 minutes cooled in an excavator 15 minutes then performed weighing (a) $\mathrm{g}$. The sample to be measured moisture content is smoothed and sifted using a 60-mesh sieve. The fine sample is weighed at $2 \mathrm{~g}$ and put in an empty, dried weigh bottle (b) $\mathrm{g}$. The weighing bottle containing the sample is put in an oven with a temperature of $100 \pm 5^{\circ} \mathrm{C}$ for 24 hours then cooled in an excavator ( \pm 15 minutes) and weighed (c) g. Sample weighing is carried out up to a constant weight (difference of $0.0002 \mathrm{~g}$ ). Moisture content is determined by using the formula:

Moisture content $(w b)=(b-c / b-a) \times 100 \%$

Description :

a : Bottle weight

$\mathrm{b}:$ Weight of bottle + sample before oven

c : Weight of bottle + sample after oven

\subsection{Roasting levels}

The peeled coffee beans are then roasted at 3 levels namely light, medium, and dark using a Probat brand machine Two Barrel Roaster-BRZ (Emmerich am Rhein-Germany) with a machine capacity of $80-100 \mathrm{~g} / \mathrm{drum}$. At the light level condition roaster is set with temperature $150^{\circ} \mathrm{C} / 300 \mathrm{~F}, 2.2 \mathrm{Mbar}, 12$ minutes, $175^{\circ} \mathrm{C} / 350 \mathrm{~F} ; 2.2 \mathrm{Mbar} ; 7.30$ minutes for the medium level, and $200^{\circ} \mathrm{C} / 400 \mathrm{~F}, 2.2 \mathrm{Mbar}, 10$ minutes for the dark level. After the roasting process was complete, the coffee beans were processed into powder using a coffee grinder and filtered using a mesh size of 100 .

\subsection{Caffeine levels UV/Vis spectrophotometry}

Caffeine analysis was conducted by UV/Vis spectrophotometry method according to Fathia et al. [10]. A total of $1 \mathrm{~g}$ of coffee powder is put in a beaker then added $150 \mathrm{~mL}$ of sterile water into it while stirring and heated. A hot coffee solution is filtered through the mouthpiece with filter paper into the Erlenmeyer. A further $1,5 \mathrm{~g}$ of calcium carbonate $\left(\mathrm{CaCO}_{3}\right)$ was added to the sample solution. The sample solution is inserted into the split funnel and then extracted 4 times, each with the addition of $25 \mathrm{~mL}$ of chloroform. The chloroform layer is taken, then the extract that still contains deposits of calcium carbonate is centrifuged. The chloroform phase that has been taken is evaporated with a rotary evaporator. Solvent-free caffeine extract is incorporated into a $100 \mathrm{~mL}$ mustard flask, diluted with actuation until the boundary mark line and homogenized. The solution is diluted again as much as $4 x$. The same treatment is done for each sample of coffee powder weighing $1 \mathrm{~g}$. The determination of wavelengths is done by detecting the absorption of standard solutions in the wavelength range of 200-700 nm using UV-Vis spectrophotometer instruments. The maximum wavelength 
obtained based on the determination of wavelength is $273 \mathrm{~nm}$. Furthermore, a standard curve is an absorbance with the concentration of each standard solution. Caffeine levels in each sample were measured with UV-Vis spectrophotometry at a wavelength of $273 \mathrm{~nm}$.

\subsection{Data analysis}

The data obtained from each chemical test parameter based on the length of fermentation time was processed using the statistical application Minitab version 16 for Windows and analyzed using ANOVA with a level of $5 \%$. If there is a significant difference from the Ftest result $(\mathrm{p}<0.05)$ a post hoc test is performed to determine the significance of the differences in each parameter and to facilitate interpretation, the resulting data is then plotted in the form of graphs.

\section{Result and discussion}

\subsection{Calibration line preparation for caffeine analysis}

The calibration solutions of caffeine in the concentration range of $0-32 \mathrm{ppm}$ and absorbance were measured on a UV/Vis spectrometer at wavelength $273 \mathrm{~nm}$ as shown in Table 1. The calibration curve for caffeine was drawn in Figure.1

Table 1. Absorbance of the calibration solutions of caffeine

\begin{tabular}{|c|c|}
\hline Concentration (ppm) & Absorbance \\
\hline 0 & 0,001 \\
\hline 4 & 0,197 \\
\hline 8 & 0,394 \\
\hline 16 & 0,787 \\
\hline 24 & 1,185 \\
\hline 32 & 1,579 \\
\hline
\end{tabular}

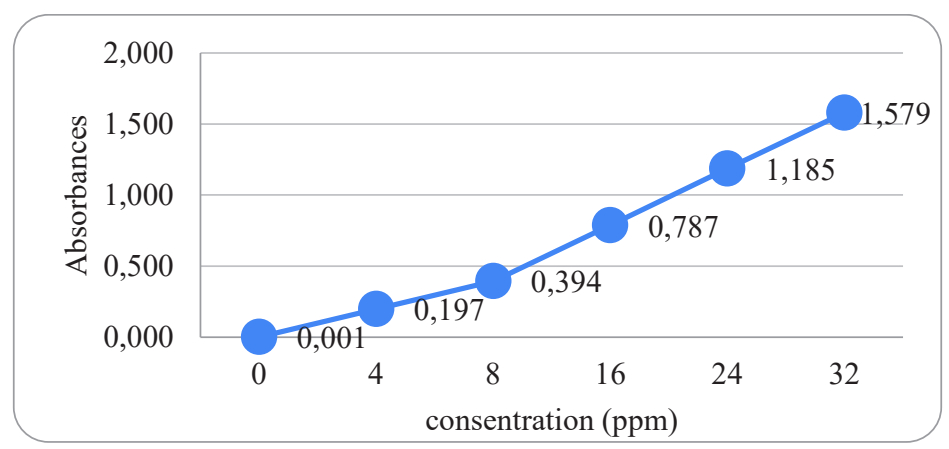

Fig. 1. Calibration curve of caffeine.

Testing the maximum wavelength of the standard solution used showed that caffeine in water solvent has two absorptions, namely at a wavelength of $205 \mathrm{~nm}$ and $275 \mathrm{~nm}$. Caffeine is a compound that has absorption at two wavelengths, namely $205 \mathrm{~nm}$ and $273 \mathrm{~nm}$ [11]. The absorption at $205 \mathrm{~nm}$ was not used because at a wavelength of about 200 it is associated with general solvent absorption. A high absorption at a test concentration of $32 \mathrm{ppm}$ can have a great chance of giving an error because the absorbance value of 3,090 indicates that $99.999 \%$ of radiation is absorbed by the compound, and only continues $8.13 \times 10-4 \%$ to the detector. 
The peak region at $273 \mathrm{~nm}$ can be associated with the absorption of the $\mathrm{C}=\mathrm{O}$ chromophore in caffeine [12]. The wavelength of 273 is used as a wavelength to identify a standard absorbance that can form a standard curve. Standard curve creation is done with six to eight standard points [13]. The absorbance of the standard between $0 \mathrm{ppm}$ to $32 \mathrm{ppm}$ was measured at a maximum wavelength of $273 \mathrm{~nm}$ with a spectrophotometer forming a calibration curve that can describe the response of the analyte system (y) to a standard concentration of known concentration.

The absorbance obtained was automatically reduced by the value of a blank containing the same solvent and reagent without the analytic (Miller and Miller 2010). The calibration curve formed makes the equation $y=3.5228 \times 10-3+0.0493 \mathrm{x}$ and the correlation coefficient is 0.99999 with the value of $y$ as absorbance, $x$ as the concentration of caffeine, and $\mathrm{R}$ as the linear regression coefficient. The results of determining linearity provide results that meet the requirements in the form of a correlation coefficient value of $>0.99$ [13]. The correlation coefficient can represent how well the experimental point is on a straight line. The value of $r$ can only be in the range $-1 \mathrm{r}+1$. When there is no relationship between points $\mathrm{x}$ and $\mathrm{y}$, then the value of $r$ will approach zero (0) [14].

\subsection{Determination of caffeine in different roasting levels}

The concentration of caffeine in different roasting levels samples of LiM coffee was determined and the average values are given in Table 2. The UV/Vis spectrometric method was used for the quantitative analysis of caffeine in different roasting levels samples of coffee beans, because this method is rapid, cheap, simple, reproducible, accurate and precise.

Table 2. The concentration of caffeine in different roasting levels

\begin{tabular}{|c|c|c|c|c|c|}
\hline No & Levels sample & $\begin{array}{c}\text { Weight } \\
\mathbf{( g )}\end{array}$ & Absorbance & $\begin{array}{c}\text { Caffeine } \\
\text { concentration (ppm) }\end{array}$ & $\begin{array}{c}\text { Caffeine concen- } \\
\text { tration (\% w/w) }\end{array}$ \\
\hline 1 & F0-Dark & 1,0003 & 0,833 & 16,948 & $1,694 \mathrm{a}$ \\
\hline 2 & F0-Medium & 1,0017 & 0,693 & 14,108 & $1,408 \mathrm{~b}$ \\
\hline 3 & F0-Light & 1,0007 & 0,615 & 12,526 & $1,252 \mathrm{c}$ \\
\hline 4 & F4-Dark & 1,0008 & 0,740 & 15,061 & $1,505 \mathrm{~d}$ \\
\hline 5 & F4-Medium & 1,0005 & 0,640 & 13,033 & $1,303 \mathrm{e}$ \\
\hline 6 & F4-Light & 1,0014 & 0,578 & 11,775 & $1,176 \mathrm{f}$ \\
\hline 7 & F8- Dark & 1,0004 & 0,712 & 14,493 & $1,449 \mathrm{~g}$ \\
\hline 8 & F8- Medium & 1,0001 & 0,581 & 11,836 & $1,184 \mathrm{f}$ \\
\hline 9 & F8- Light & 1,0016 & 0,531 & 10,822 & $1,080 \mathrm{~h}$ \\
\hline 10 & F12- Dark & 1,0073 & 0,818 & 16,644 & $1,652 \mathrm{a}$ \\
\hline 11 & F12- Medium & 1,0008 & 0,563 & 11,471 & $1,146 \mathrm{i}$ \\
\hline 12 & F12-Light & 1,0001 & 0,581 & 11,836 & $1,184 \mathrm{f}$ \\
\hline
\end{tabular}

Note: $\mathrm{F} 0=$ no-fermentation; F1 $=$ fermented for $4 \mathrm{~h} ;$; F2 = fermented for $8 \mathrm{~h}, ; \mathrm{F} 3=$ fermented for $12 \mathrm{~h}$ *The numbers followed by the same letter showed no significant difference at a confidence level of $95 \%$.

Based on Table 2 shows that all samples contain large amounts of caffeine with various concentrations. The level concentration of caffeine in light roast samples in the range of 10,80 ppm-12,52 ppm, medium roast samples in the range of 11,46 ppm-14,08 ppm, and dark roast samples in the range of 14,49 ppm-16,94 ppm. Liberica coffee fermented on roasting levels shows a significant difference in caffeine content. In this study, an analysis of the effect of fermentation and roasting levels caffeine was carried out. The caffeine concentrations depend principally on the genus or variety of coffee, the geographical origin (agro-ecology) and the caffeine extraction method from coffee beans [15]. Roasting aims to reduce water content, cause color changes, and form a specific aroma. Organoleptic testing of the bitterness of 
steeping coffee grounds, the panelists gave an assessment that the longer the brewing of the coffee grounds the steeper the bitterness. During roasting the caffeine content contributes to the formation of flavor in the brewed coffee grounds. According to the results of Yusianto and Widyotomo [16], steeping coffee grounds that are roasted for 5 and 10 minutes based on panelist tests taste slightly bitter and roasted for 20 minutes is very bitter.

The caffeine concentration in coffee beans that are suitable for human health related to the data in Table 2 is recommended in medium level to get mood booster effect and health benefits. Caffeine is known to have an additive effect and has a positive effect on humans with a low dose of $400 \mathrm{mg}$ such as increased arousal, increased joy, peace, and fun [17], and according to SNI 01-7152-2006 [18], the maximum consuming caffeine directly or mixed in food or drink is $150 \mathrm{mg}$ /day or $50 \mathrm{mg} / \mathrm{cup}$. Caffeine, including purine compounds that are part of nucleic acids, RNA, and DNA which only gives a bitter taste of about $10-30 \%$ of brewed coffee [19]. In roasting there is a pyrolysis process that causes oxidation, reduction, hydrolysis, polymerization, decarboxylation and other chemical changes to form compounds that determine the aroma and taste of brewing coffee grounds. Caffeine can melt at a temperature of $2340 \mathrm{C}$ to $239^{\circ} \mathrm{C}$ if it does not contain water and sublimates at a lower temperature of $1780 \mathrm{C}$. Caffeine is readily soluble in hot water and in chloroform, but slightly soluble in cold water, alcohol and some other organic solvents. Besides caffeine, coffee also contains tannin, glucose, fat, protein and cellulose.

\section{Conclusions}

The caffeine content in Liberica cv Liberoid Meranti coffee beans fermented by hydrolytic bacteria at roasting levels on light $\left(150^{\circ} \mathrm{C}\right)$, medium $\left(175^{\circ} \mathrm{C}\right)$, dark $\left(200^{\circ} \mathrm{C}\right)$ had changes significantly different concentrations. Fermentation method and roasting levels of Liberica coffee cherry influenced the caffeine content and sensory acceptability.

\section{References}

1. T. Seifu, Level of caffeine in raw and roasted coffee bean varieties of Hararghe, Ethiopia [tesis] (Haramaya (ET), Haramaya University, 2018)

2. P. Rahardjo, Kopi (Penebar Swadaya, Bogor, 2012)

3. BPS Badan Pusat Statistik, Statistik Kopi Indonesia (Badan Pusat Statistik, Jakarta, 2017)

4. B. Gebeyehu, S. Bikila, Am. J. Appl. Chem. 3, 2, 69-76 (2015)

5. Crozier, H. Ashihara, F. Tomás-Barbèran, Teas, Cocoa, and Coffee: Plant Secondary Metabolites and Health (John Wiley \& Sons, West Sussex (UK), 2011)

6. Fredholm, Methylxanthines (Springer, Stockholm (SE), 2011)

7. M. Salihovic, A. Sapcanin, M. Pazalja, A. Alispahic, A. Dedic, E. Ramic, Bull. Chem. Technol. Bosnia Herzegovina. 43, 1-4 (2014)

8. B. Martono, J. Wet. Environ. Manag. 5, 1 (2017)

9. Gardjito, Murdijati, D. Rahardian AM., Kopi (Penerbit Kanisius, Yogyakarta, 2011)

10. R.A. Fathia, A. Yossy, P. Tikarahayu, M.Y. Azis, D.W. Camelina, R.M. Putra, BIOTIKA. 16, 2 (2018)

11. S. Ahuja, M. Dong, Handbook of Pharmaceutical Analysis by HPLC (Elsevier Ltd, Oxford (UK), 2005)

12. S. Dobrinas, Soceanu, Popescu, Stanciun, Smalberger, Sci. Study Res. 14, 2, 71-78 (2013)

13. The Association of Analytical Communities, Guidelines for Dietary Supplements and Botanicals (AOAC International, Maryland (US), 2013) 
14. J. Miller, J.C. Miller, Statistics and Chemometrics for Analytical Chemistry edisi ke-6 (Pearson Education Limited, Harlow (UK), 2010)

15. E. Demissie, G. Woyessa, A. Abebe, Sci. Study Res. 17, 2, 109-123 (2016)

16. Yusianto, S. Widyotomo, Pelita Perkeb. 29, 3, 220-239 (2013)

17. C. Wilson, Toxicol. Reports. 5, 1140-1152 (2018)

18. SNI 01-7152-2006, Indonesian National Standard, Food Additives-Requirements for Flavors and Use in Food Products (2006)

19. R.J. Clarke, R. Macrae, Coffee Technology (Volume 2) (Elsevier Applied Science, London and New York, 1989) 